\title{
Information technology and industry change: view from an industry level of analysis
}

Journal of Information Technology (2005) 20, 211-212. doi:10.1057/palgrave.jit.2000052

$\mathbf{T}$ he ability of firms to gain competitive advantage from information and communication technologies (ICTs) has long been an important theme in the information systems (IS) field. Most research in this area has been pursued at the individual and organizational level of analysis (Gregor and Johnston, 2001; Johnston and Gregor, 2000). Extrapolations to an understanding of these developments as an industry-level phenomenon have typically been based on aggregation of firm-level data.

The papers in this special issue of the Journal of Information Technology (JIT) take a different view and argue that ICT-enabled competitive advantage is best investigated from the industry level of analysis. In fact, the authors argue that the changes from and impacts of ICT are obscured by the field's current focus on the firm and interorganizational levels of analysis. When the focus of investigation is at the industry level, it quickly becomes apparent that individual firms have little ability to influence the course of events. Certainly, a few industry leaders may change the game for the rest, but even they may not be immune to the unintended consequences of their own successes (or failures).

Examples of how ICT is changing the competitive landscape at the industry level are easy to find. The air travel industry, for example, has been restructured as a consortia organized around four major reservation systems. The mortgage industry has changed and has been partially restructured. Automated underwriting software and the Internet made this industry transparent, nationally competitive, and reduced the average approval time of a mortgage application from 6 weeks, a decade ago, to just 3-5 minutes today. In the real estate industry, the agent- and brokercontrolled information monopoly, the multiple listing service (MLS) available in the past to agents and brokers exclusively, was broken; MLS listings appear on websites today and are publicly available to anyone.

Each contribution to this special issue has attempted to apply what was learned at the industry level of analysis to a better understanding of the aggregate effects of ICT investments. Among the effects found in these studies are impacts on occupations (e.g., performance effects, changes in employment, nature of work, use of tools), impacts on industry structure (e.g., the potential of disintermediation of firms and new value chains, newly conceived valueadding activities, speed of delivery and processing, net- works of companies within a value chain) as well as industry consolidation or other structural impacts (e.g., new business models, collective action, influence of standards, public policy and regulation).

Depending on the level of analysis that is used to study organizations, one may have different conclusions about the effects of ICT. One benefit of conducting research at the industry level is that many issues have surfaced, which would never be readily detected when focusing on the individual firm. Unintended effects may not be detectable (or at least not reliably or quickly) at the firm level, but become quite visible at the industry level of analysis. A recent example is the trend toward outsourcing, which would not be possible without ICTs and the Internet. The impact may not seem large when focusing on a given individual firm; in fact, some may call this pursuing a smart strategy. However, looking at outsourcing at the industry level allows us to see an emergent global trend with potentially devastating impact on the economy.

A number of programs in the Directorate for Computer and Information Science and Engineering (CISE) at the National Science Foundation (NSF) have long supported research conducted at the industry level of analysis. Two of the contributions to this special issue ('Redefining access: uses and roles of information and communication technologies in the US residential real estate industry from 19952005 ' and 'Exploring the consequences of IOS use at the industry level of analysis: evidence from the US home mortgage industry') were funded by NSF.

It is important to understand that industries can be powerful actors in their own right. An industry may mobilize powerful forces that produce important effects on the individual firms within that industry. In that sense, industry membership could be critical for success or it might cause failure regardless of the actions of the individual firm.

Four different industries are investigated in the studies in this special issue - real estate (service), mortgage (financial), video game (software and information technology), and automotive (manufacturing) industries. The following four papers comprise this special issue on 'IT and industry change: view from an industry-level of analysis':

1. 'Redefining access: uses and roles of information and communication technologies in the US residential real estate industry from 1995-2005,' by Steve Sawyer, 
Rolf Wigand and Kevin Crowston. This paper provides a decade-long retrospective on the impact of new ICT on the real estate industry. These authors show how this industry has undergone changes in structure, valueadding activities and practice, and has met threats such as disintermediation and the advent of the Internet.

2. 'Exploring the consequences of interorganizational systems (IOS) use at the industry level of analysis: evidence from the US home mortgage industry,' by Charles Steinfield, Lynne Markus and Rolf Wigand. They show in their contribution, how IOS can have influences extending beyond the organization or pair of organizations implementing them. These authors identify three types of industry-level effects when examining the use of interorganizational IT-driven coordination systems: performance effects, structural effects and collective actions.

3. 'Information technology (IT) and the video game industry: tensions and mutual shaping' by JP Allen and Jeffrey Kim. They examine the influence of IT on the video game industry. They do so by conceptualizing technology as an external factor causing industry change, that is, treating IT and video games as two industries that may influence each other. They demonstrate these relationships and also discover intriguing interdependencies by creating complementary or replacement innovations that may influence the other industry and change the IT industry itself.
4. 'Collaboration, autonomy and control: a study of automotive ICT for the "3 Day Car",' by Mickey Howard. His research shows how ICTs are crucial in re-shaping industry structures that enhance customer responsiveness and the ability to build to order. The paper presents findings from a longitudinal project during a critical period for the industry, where organizations adopting Web-enabled ICT seek to gain collaborative capabilities and competitive advantage.

The industries addressed here are diverse and unique, yet they all rely on ICT and have been fundamentally changed by ICT. The objective of this special issue is to provide a deeper understanding of the relationships among information, ICTs, industry and change.

Suzanne Iacono, Rolf $T$ Wigand

\section{References}

Gregor, S. and Johnston, R. (2001). Theory of Inter-organizational Systems: Industry structure and processes of change, Paper presented at the 34th Hawai'i International Conference on Systems Sciences, Maui, 3-6 January 2001.

Johnston, R. and Gregor, S. (2000). A Theory of Industry-level Activity for Understanding the Adoption of Interorganizational Systems, European Journal of Information Systems 9: 243-251. 